\title{
ASSESSMENT OF PHYSICAL PROPERTIES OF PET-FOOD BASED ON WHEAT MIDDLINGS AND MEAT MEAL
}

\author{
Simone Pascuzzi ${ }^{1}$, Pawel Sobczak ${ }^{2}$, Artur Przywara ${ }^{2}$, Magdalena Kachel ${ }^{2}$, Francesco Santoro ${ }^{1}$ \\ ${ }^{1}$ University of Bari Aldo Moro, Italy; ${ }^{2}$ University of Life Sciences in Lublin, Poland \\ pawel.sobczak@up.lublin.pl
}

\begin{abstract}
Considering the popularity of dry pet food, its market and production are constantly increasing. The quality of the food and the source of raw materials used for its production become as important as in the production of food for human consumption. The aim of the study was to assess the basic physical characteristics of the pet food produced from wheat middlings and meat meal using the extrusion process. The composition of individual samples was as follows: sample A - meat meal $25 \%$, wheat meal $75 \%$, moisture content of $30 \%$; sample B - meat meal $25 \%$, wheat meal $75 \%$, moisture content of $25 \%$; sample C - meat meal $25 \%$, wheat meal $75 \%$, moisture content of $20 \%$; sample D - meat meal $50 \%$, wheat meal $50 \%$, moisture content of $30 \%$; sample E - meat meal $50 \%$, wheat meal $50 \%$, moisture content of $25 \%$; sample $\mathrm{F}$ - meat meal $50 \%$, wheat meal $50 \%$, moisture content of $20 \%$. The compounds composed in this way were subject to the extrusion process to obtain characteristic animal cookies. After the initial tests, the following extrusion process parameters were selected: first heater section: $100^{\circ} \mathrm{C}$, second heater section: $120^{\circ} \mathrm{C}$, head: $120^{\circ} \mathrm{C}$, die: oval $2.5 / 15 \mathrm{~mm}, 37.5$ mm diameter, screw: $800 \mathrm{~mm}, \varnothing 60 \mathrm{~mm}$., screw rotation: $100 \mathrm{rpm}$. Properties, such as the degree of expansion, cutting test (biting) and durability, were assessed. The moisture content of raw material before the extrusion process had the highest impact on the physical characteristics of the final product. Statistically significant differences in the cutting test were recorded, depending on the share of individual components and the moisture content.
\end{abstract}

Keywords: physical properties, extrusion cooking, pet-food, mechanical durability.

\section{Introduction}

Extrusion process is used in many branches of food processing. The main assumption of the process is the treatment of raw materials at high temperature and pressure (the so-called barothermic processing). It is widely used in the fodder industry for treating soybean meal, as thanks to the parameters of the extrusion process high content of anti-nutritional compounds present in soybean is eliminated [1].

The market of pet food is developing very quickly, along with the ever increasing number of pets. Additionally, the popularity of dry food increases, as it is considered to be the most favourable when it comes to feeding the animals. In recent years, the source of raw materials used for pet food production became important [2]. Raw materials coming from sustainable farms are increasingly used, and so are fish and seafood originating from sustainable and environmental friendly fishing [3; 4].

The basic components of feed of the pet food type include:

- mixtures of ground grain (maize, wheat, sorghum, and soybeans);

- soybean meal;

- meat meal and meat-and-bone meal;

- animal fats, and others [5].

In sustainable agriculture, it is important to process all by-products, which are produced and can be used for various purposes. Production of different types of biofuels represented by pellets made of oily raw materials is popular in this regard [6-10]. In addition to their purposeful and complete utilization, works are carried out on designing optimal harvesting techniques, fertilization, and even computerized planning of plantings [11-14]. Besides the utilisation and processing rates, also research is carried out in the material quality, content of micro- and macroelements and the impact on the environment $[15 ; 16]$.

The aim of this study was to produce feed of the pet food type using the extrusion process, and to evaluate the basic strength parameters of the obtained food.

\section{Materials and methods}

The test material consisted of 6 different compounds based on meat meal and wheat middlings mixed in various proportions. The research material came from sustainable farms located in Poland. 
The composition of each individual compound and its moisture content before the extrusion process is shown below:

In the research, the following designations were adopted:

- sample A - meat meal $25 \%$, wheat meal $75 \%$, moisture content of $30 \%$;

- sample B - meat meal $25 \%$, wheat meal $75 \%$, moisture content of $25 \%$;

- sample C-meat meal $25 \%$, wheat meal $75 \%$, moisture content of $20 \%$;

- sample D - meat meal $50 \%$, wheat meal $50 \%$, moisture content of $30 \%$;

- sample E - meat meal $50 \%$, wheat meal $50 \%$, moisture content of $25 \%$;

- sample F - meat meal $50 \%$, wheat meal $50 \%$, moisture content of $20 \%$.

Before the extrusion process $5 \mathrm{~kg}$ portions of each compound were weighted, which were humidified to the moisture content of $20 \%, 25 \%$ and $30 \%$, respectively.

These prepared allotments of respective compounds were subject to the extrusion process using a single-screw extruder S-60.

After initial trials the following parameters of the extrusion process were selected:

- first heating section: $100{ }^{\circ} \mathrm{C}$;

- second heating section: $120^{\circ} \mathrm{C}$;

- head: $120^{\circ} \mathrm{C}$;

- die: oval 2.5/15 mm., $37.5 \mathrm{~mm}$ in diameter;

- screw: $800 \mathrm{~mm} ., \varnothing 60 \mathrm{~mm}$. (L/D = 13.3);

- screw rotational speed: $100 \mathrm{rpm}$.

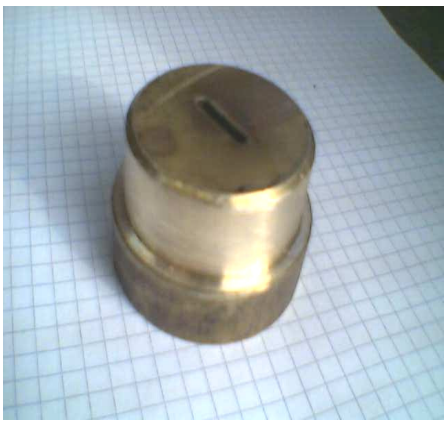

Fig. 1. Extruder die head

Moisture content of the material and the obtained food was determined using the dry oven method in accordance to PN-EN-ISO 18134-3:2015-11 standard [17].

Before the extrusion process, the following physical properties of the compounds were assessed:

- angle of repose [18];

- chute angle [19];

- bulk density [20];

- shaken density [20];

- average particle size [21].

Obtained pet food cakes, after drying on screens to the final moisture content of $10 \%$, were subject to the following tests.

1. The degree of expansion was calculated from the formula:

$$
S e=\frac{h \cdot g}{2.5 \cdot 15} \cdot 100
$$

where $S e$ - degree of expansion, \%;

$h$ - height of the sample, $\mathrm{mm}$;

$g$ - thickness of the sample, $\mathrm{mm}$;

2.5 and 15 - dimensions of the die head, $\mathrm{mm}$. 
2. The cutting test was performed using a TA.XT plus texture analyser with the blade with cutting edge angle of $45^{\circ}$ until the sample was cut into half.

3. Kinetic durability of the pet food was measured in accordance with Pfost method PN-R-64834 [22].

\section{Results and discussion}

Physical properties of the compounds prior to the extrusion process are shown in Table 1. The obtained compounds had similar physical characteristics, which allows to omit their effect on the extrusion process and the strength properties of the obtained pet food.

Table 1

Physical properties of the raw materials and compounds before the extrusion process

\begin{tabular}{|c|c|c|c|c|c|}
\hline Raw material & $\begin{array}{c}\text { Angle of } \\
\text { repose, }\end{array}$ & $\begin{array}{c}\text { Chute angle, } \\
\mathbf{o}\end{array}$ & $\begin{array}{c}\text { Bulk density, } \\
\mathbf{k g} \cdot \mathbf{m}^{-3}\end{array}$ & $\begin{array}{c}\text { Shaken } \\
\mathbf{d e n s i t y}, \\
\mathbf{k g} \cdot \mathbf{m}^{-3}\end{array}$ & $\begin{array}{c}\text { Average } \\
\text { particle size, } \\
\mathbf{m m}\end{array}$ \\
\hline Wheat middlings & 28 & 36 & 587 & 1107 & 0.64 \\
\hline Meat meal & 35 & 35 & 577 & 1077 & 0.42 \\
\hline $\begin{array}{c}\text { Compound (with } \\
25 \% \text { share of } \\
\text { meat meal }\end{array}$ & 31 & 36 & 585 & 1085 & 0.56 \\
\hline $\begin{array}{c}\text { Compound (with } \\
50 \% \text { share of } \\
\text { meat meal }\end{array}$ & 33 & 35 & 582 & 1092 & 0.62 \\
\hline
\end{tabular}

The degree of expansion of the obtained pet food is depicted in Fig. 2. The degree of expansion depended on the moisture content of the compound. The highest degree of expansion was obtained for the compounds with the moisture content of $20 \%$. It ranged between 1.83 and $1.96 \%$. In the case of the mixtures with the moisture content of $30 \%$ the degree of expansion was 0.95 and $0.63 \%$ accordingly. As shown by the research results, the degree of expansion is also correlated with the composition of the compound. In the case of compounds with oat sharps and maize meal the degree of expansion ranged from 2 to 4 for the compounds of $30 \%$ and $50 \%$ of oat sharps with maize meal [23].

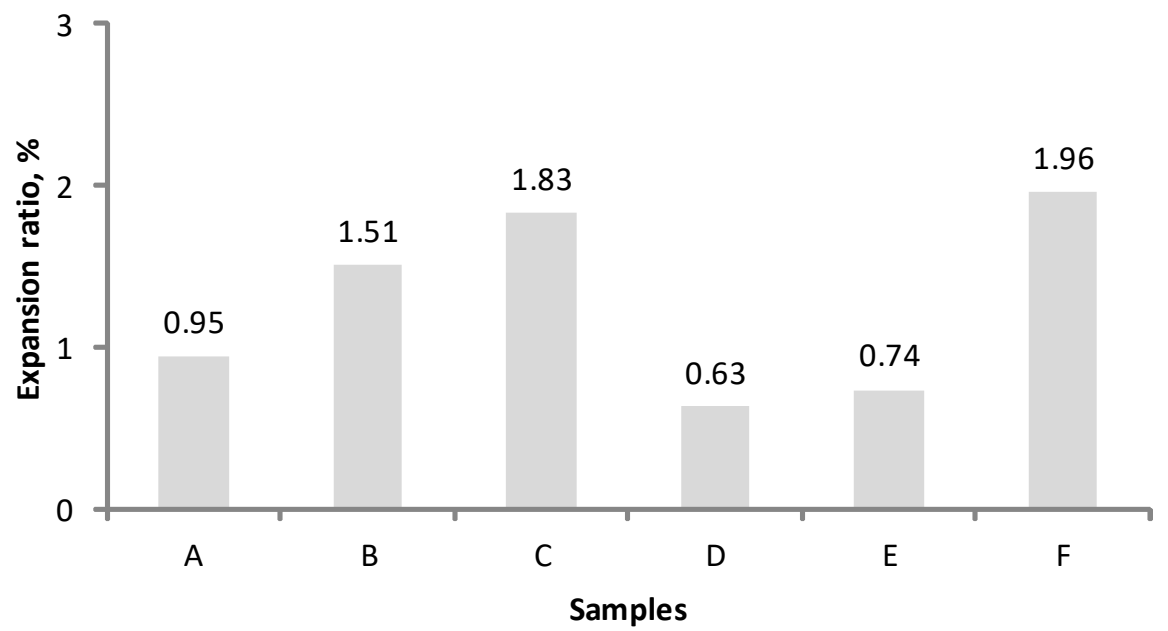

Fig. 2. Degree of expansion of particular samples

When measuring the cutting force for individual pet food an inverse relationship was observed (Fig. 3), i.e. the samples with the moisture content of $30 \%$ were characterised by the highest cutting force of $151.2 \mathrm{~N}$ for compound $\mathrm{A}$ and $90.1 \mathrm{~N}$ for compound $\mathrm{D}$. The samples with lower moisture content $(\mathrm{C}$ and $\mathrm{F})$ were characterised by lower cutting force of $23.2 \mathrm{~N}$ and $20.2 \mathrm{~N}$, respectively. Sobczak et al. (2007) carried out research on samples with meat meal, soyabean meal, and maize meal [24]. In that study the value of the cutting force for the obtained extrudates varied between 3.6 and 13.4 N, which evidenced high fragility of the samples. In contrast, the compounds of oat sharps, with 
admixture of 20 and $30 \%$ of maize meal, subject to the extrusion process were characterized by the the cutting force ranging between 10 and $20 \mathrm{~N}$ [23; 25].

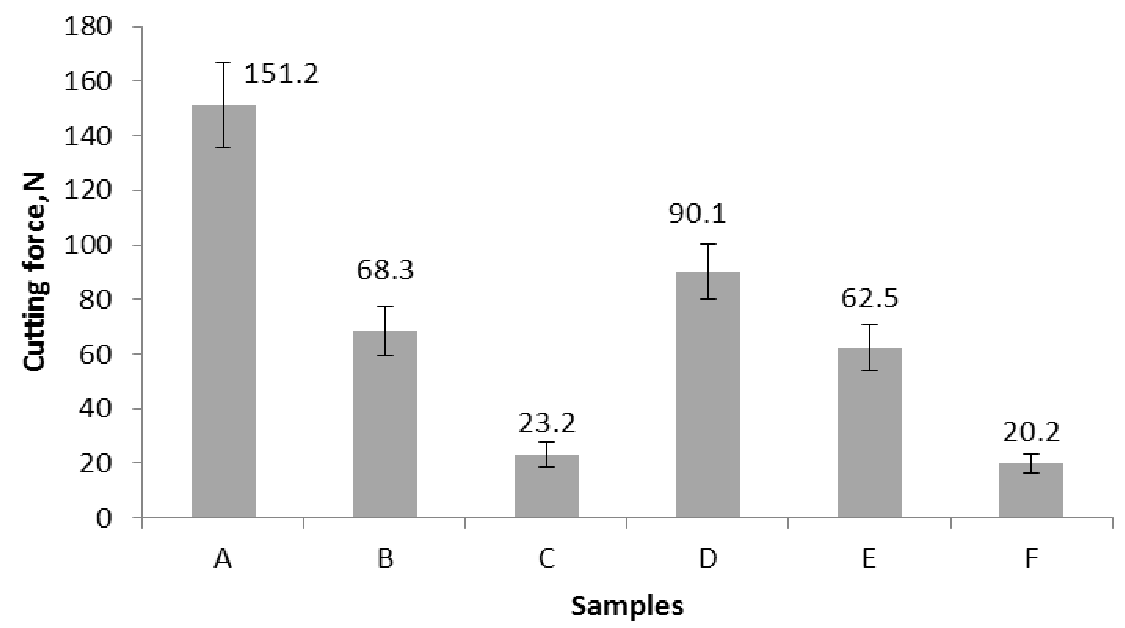

Fig. 3. Value of cutting force with standard deviation for particular samples

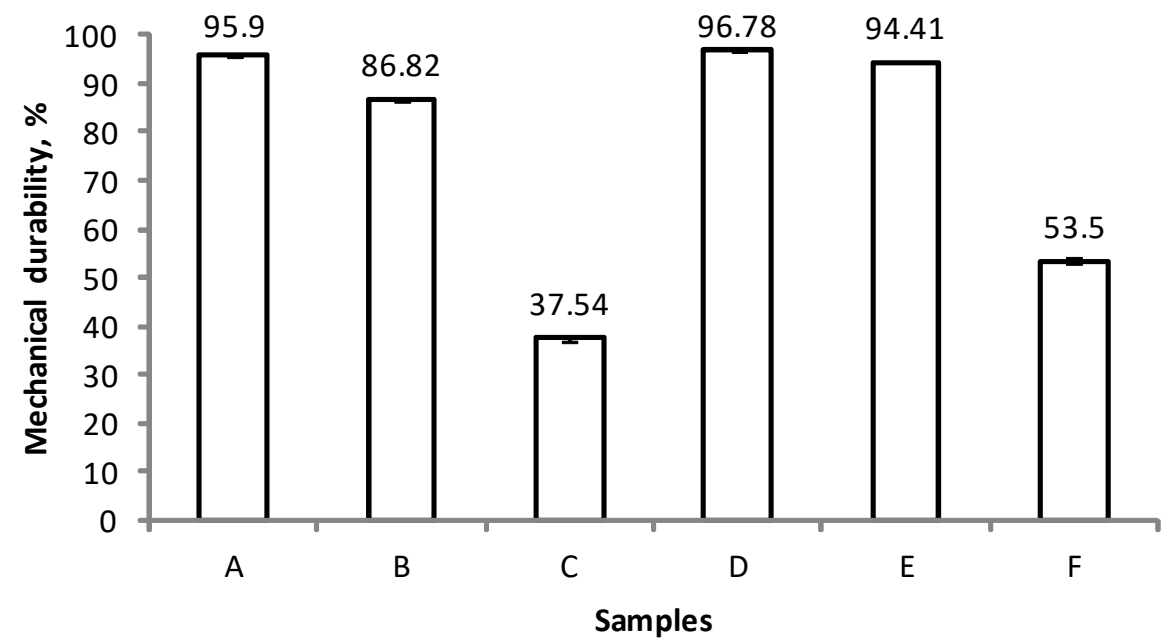

Fig. 4. Mechanical durability of individual samples measured in accordance to Pfost method

The highest mechanical durability of pet food was observed for the samples with the moisture content of $30 \%$ (Fig. 4). In the case of samples with the initial moisture content of $20 \%$, i.e. samples $\mathrm{C}$ and $\mathrm{F}$, a significant decrease of mechanical durability was observed. The samples with the initial moisture content of $25 \%$ were characterised by the mechanical durability of $86.82 \%$ (sample B) and $94.41 \%$ (sample E). Mechanical durability indicates the integrity of pellets and their resistance to pouring. For granulated samples of wheat middlings the mechanical durability was only within the 90$98 \%$ range $[24 ; 26]$.

\section{Conclusions}

1. Initial moisture content of the compounds influences the quality of extruded pet food.

2. In the case of compounds $\mathrm{A}$ and $\mathrm{C}$, the increase of the compound moisture content by $50 \%$ (from 20 to $30 \%$ ) resulted in an over sevenfold increase of the cutting force, while the mechanical durability of these compounds increased more than twice.

3. When it comes to the degree of expansion, the inverse relationship was observed. The increase of the moisture content of the compound prior to extrusion by $50 \%$ (samples A and C) resulted in reduction of the degree of expansion by half.

4. The share of meat meal, equal to $50 \%$ or $25 \%$, in the pet food resulted in the change of its durability. 


\section{References}

[1] Sobczak P., Zawiślak K., Panasiewicz M., Mazur J., Kocira S., Żukiewicz-Sobczak W. Impact of heat treatment on the hardness and content of anti-nutritious substances in soybean seeds. Carpathian Journal of Food Science and Technology. Vol 10(5), 2018, 46-52.

[2] Santoro F., Anifants A.S., Ruggiero G., Zavadskiy V., Pascuzzi S. Lightning Protection Systems Suitable for Stables: A Case Study. Agriculture, vol. 9(4), 2019, 72 - DOI: 10.3390/agriculture9040072.

[3] Żukiewicz-Sobczak W., Sobczak P., Rogóż A., Wojtyła-Buciora P., Kozak M., Zagórski J. Valuation of the content of selected elements in herbs cultivated in organic farms in the Lublin region. Proceedings Paper, Farm Machinery And Processes Management In Sustainable Agriculture, 2017, 461-464, DOI: 10.24326/fmpmsa.2017.83.

[4] Anifantis A.S., Pascuzzi S., Scarascia Mugnozza G. Geothermal source heat pump performance for a greenhouse heating system: An experimental study. Journal of Agricultural Engineering, vol. 47(3), 2016, pp.164-170.

[5] Przywara A., Kachel M., Koszel M., Leszczyński N., Kraszkiewicz A., Anifantis A. S. The influence of digestate on the static strength of spring rapeseeds (Brassica napus var. arvensis). Sustainability, vol. 11(7), 2019, 2133.

[6] Russo G., Verdiani G., Anifantis A.S. Re-use of agricultural biomass for nurseries using proximity composting. Contemporary Engineering Sciences, vol. 9(24), 2016, pp. 1151-1182.

[7] Kachel M., Matwijczuk A., Sujak A., Czernel G., Niemczynowicz A., Nowicka A.. The influence of copper and silver nanocolloids on the quality of pressed spring rapeseed oil. Agronomy, vol. 9(10), 2019, 643.

[8] Kachel-Jakubowska M., Matwijczuk A., Gagoś M. Analysis of the physicochemical properties of post-manufacturing waste derived from production of methyl esters from rapeseed oil. Int. Agrophys., vol. 31(2), 2017, pp. 175-182, DOI: https://doi.org/10.1515/intag-2016-0042

[9] Kraszkieicz A., Kachel M., Parfiniuk S., Zając G., Niedziółka I., Sprawka M. Assessment of the possibility of using hemp biomass (Cannabis sativa L.) for energy purposes: a case study. Appl. Sci.-Basel, vol. 9(20), 2019, 4437, DOI: 10.3390/app9204437.

[10] Kraszkiewicz A., Sobczak P., Żukiewicz-Sobczak W., Niedzióka I., Zawiślak K., Dula M. Movement of chemical elements in ash on the example of a process of combustion corn straw briquettes in a low power boiler. Rocznik Ochrona Środowiska, vol. 21, 2019, pp. 1294-1306.

[11] Anifantis A.S., Camposeo S., Vivaldi G.A., Santoro F., Pascuzzi S. Comparison of UAV photogrammetry and 3D modeling techniques with other currently used methods for estimation of the tree row volume of a super-high-density olive orchard. Agriculture (Switzerland), vol. 9(11), 2019, 233.

[12] Bulgakov V., Pascuzzi S., Adamchuk V., Ivanovs S., Pylypaka S. A theoretical study of the limit path of the movement of a layer of soil along the plough mouldboard. Soil \& Tillage Research, vol. $195,2019,104406$.

[13] Bulgakov V., Pascuzzi S., Santoro F., Anifantis A.S. Mathematical model of the plane-parallel movement of the self-propelled root-harvesting machine. Sustainability, vol. 10(10), 2018, pp. 378 - DOI: 10.3390/su10103614.

[14] Przywara A. The impact of structural and operational parameters of the centrifugal disc spreader on the spatial distribution of fertilizer. Agriculture and Agricultural Science Procedia, vol. 7, 2015, pp. 215-222.

[15]Leszczyński B., Żukiewicz-Sobczak W., Sobczak P., Santoro F. Bioaerosol and smog as determinants of human population health. Health Problems of Civilization, vol. 13(3), 2019, pp. 233-237, DOI: $10.5114 /$ hpc.2019.86117

[16] Nadulski R., Masłowski, A., Mazurek A., Sobczak P., Szmigielski M., Żukiewicz-Sobczak W., Niedziółka I., Mazur J. Vitamin C and lutein content of northern highbush blueberry (Vaccinium corymbosum L.) juice processed using freezing and thawing. Journal of Food Measurement and Characterization, vol. 13(4), 2019, pp. 2521-2528, DOI: 10.1007/s11694-019-00172-x.

[17] PN-EN-ISO 18134-3:2015-11. Solid biofuels — Determination of moisture content - Oven dry method - Part 3: Moisture in general analysis sample. Polish Committee for Standardization: Warsaw, Poland, 2015 (In Polish). 
[18] PN-65/Z-04005 - Determination of the chute angle. Polish Committee for Standardization: Warsaw, Poland, 1965 (In Polish).

[19] PN-73R-74007 - Determination of the angle of repose. Polish Committee for Standardization: Warsaw, Poland, 1973 (In Polish).

[20]PN-EN ISO 8460:1999. Determination of bulk density and shaken density. Polish Committee for Standardization: Warsaw, Poland, 1999 (In Polish).

[21] PN-89 R-64798 Feed - determination of fragmentation. Polish Committee for Standardization: Warsaw, Poland, 1989 (In Polish).

[22] PN-R-64834:1998. Kinetic strength testing of granules. Polish Committee for Standardization: Warsaw, Poland, 1998 (In Polish).

[23] Mazurkiewicz J., Gustaw W., Mleko S., Achremowicz B. 2003. Tekstura ekstrudatów o podwyższonej zawartości surowców owsianych (Texture of extrudates with an increased content of raw materials made of oat). Żywność, 4(37), 86-96 (In Polish).

[24] Sobczak P., Zawiślak K. 2007. Wpływ dodatku sorbitolu na wybrane cechy produktu po aglomeracji wysokociśnieniowej (The influence of sorbitol additive on selected product features after high-pressure agglomeration). Inżynieria Rolnicza, vol. 5(93), 2007, pp. 383-388 (In Polish).

[25] Mendonca S. Grossman M.V.E., Verhe R. Com bran as a fiber source in expanded snacks. Lebens. Wiss. U Technol., vol. 33, 2000, pp. 2-8.

[26]Zawiślak K. Wpływ kształtu powierzchni rolek wytłaczających na trwałość granulatu (Influence of the shape of the surface of extruding rolls on durability of the granulated product). Inżynieria Rolnicza, vol. 7, 2006, pp. 475-483 (In Polish). 